Research Article

\title{
Sustainability Design Considerations for Timber-Concrete Composite Floor Systems
}

Md Abdul Hamid Mirdad (D, Hossein Daneshvar, Thomas Joyce, and Ying Hei Chui

Department of Civil and Environmental Engineering, 9211116 Street NW, University of Alberta, Edmonton, AB T6G1H9, Canada

Correspondence should be addressed to Md Abdul Hamid Mirdad; mdabdul@ualberta.ca

Received 19 December 2020; Revised 1 March 2021; Accepted 4 March 2021; Published 16 March 2021

Academic Editor: Claudio Mazzotti

Copyright (c) 2021 Md Abdul Hamid Mirdad et al. This is an open access article distributed under the Creative Commons Attribution License, which permits unrestricted use, distribution, and reproduction in any medium, provided the original work is properly cited.

\begin{abstract}
Over the last few decades, there has been growing interest in the use of low-carbon materials to reduce the environmental impacts of the construction industry. The advent of mass timber panels (MTP), such as cross laminated timber (CLT), has allowed structural engineers to specify a low-carbon material for a variety of floor design considerations. However, serviceability issues such as vibration and deflection are limiting the construction of longer span timber-only floor systems and have encouraged the development of timber-concrete composite (TCC) systems. The use of concrete would negatively impact on the carbon footprint of the TCC floor system and should be minimized. The purpose of this study was to study the impact on embodied carbon in the TCC system, when the ratio of timber and concrete was varied for specific floor spans. Two MTP products were considered, CLT and glued laminated timber (GLT). The floors were designed to satisfy structural, acoustic, and vibration criteria, and the results were presented in the form of span tables. It was found that using thicker MTP instead of adding concrete thickness to meet a specific span requirement can lead to lower embodied carbon values. Increasing concrete thickness for long-span floor systems led to a reduction in allowable floor span due to the vibration criterion being the controlling design parameter. Increasing timber thickness also resulted in higher strength and stiffness to weight ratios, which would contribute toward reducing the size of lateral load resisting systems and foundations, resulting in further reductions in the embodied carbon of the entire structure.
\end{abstract}

\section{Introduction}

In recent years, the use of timber in multistorey residential and commercial buildings has increased worldwide, primarily inspired by consciousness surrounding the sustainability of timber as the primary structural material $[1,2]$. Timber structures are generally associated with lower levels of embodied carbon due to lower emissions during the manufacturing of the timber products and the construction process. In addition, some life cycle accounting practices permit the inclusion of carbon sequestered from the atmosphere during tree growth that is captured within timber products for the duration of their life $[3,4]$. Therefore, timber in construction can reduce greenhouse gas (GHG) emission in the atmosphere which is a major contributor to global warming. A new generation of engineered mass timber products known as mass timber panel (MTP), for example, glued laminated timber (GLT) and cross laminated timber (CLT), has the structural capacities to be used as a lowcarbon alternative to steel and concrete for gravity and lateral load resisting systems in structures.

Construction with mass timber is approximately $25 \%$ faster than similar on-site concrete construction. It also requires $90 \%$ less construction traffic and $75 \%$ fewer workers which yields a much quieter job site [5]. The lighter weight and lower stiffness of timber-only floors can make them more susceptible to serviceability limit states such as vibrations and excessive deflections while satisfying the strength requirements. Therefore, in timber-concrete composite (TCC) floor systems, a structural concrete topping layer is provided over the timber beam or mass timber panel (MTP). The two components are connected by mechanical connectors, as shown in Figure 1, such as dowels 


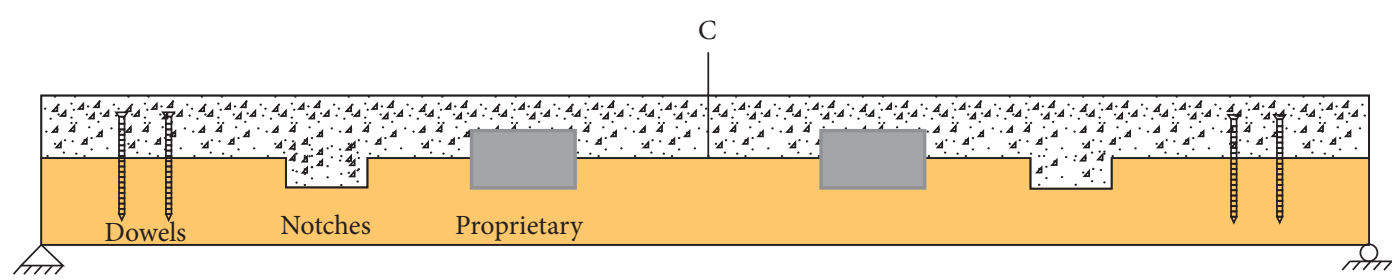

(a)

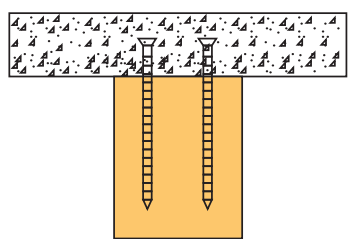

(b)

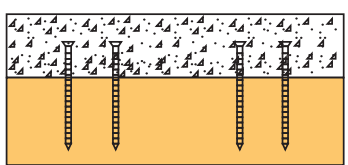

(c)

Figure 1: (a) Longitudinal section of a TCC system with dowel, notched, or proprietary connectors; cross section of a TCC floor (b) with timber beam and (c) with MTP.

(e.g., self-tapping screw (STS)), notches, or proprietary connectors (e.g., glued in plate/HBV plate). The added concrete increases the floor mass and stiffness which subsequently mitigates the vibrations and excessive deflection issues [6-8].

In TCC construction, the concrete slab resists compressive stress while timber primarily resists tensile stress generated by an out-of-plane bending action. In reinforced concrete design, the tensile strength of concrete is often neglected, and steel reinforcement is installed to resist the tensile stresses caused by bending. In the ultimate limit state design, the concrete is assumed to crack to about $2 / 3$ of its depth under bending [9]. In TCC, this cracked area is replaced by the timber cross section. In TCC, minimum steel reinforcements are provided only to control and limit the cracking. The mechanical connector transfers the shear force between timber and concrete to provide a desired partial composite action. Using a timber panel instead of a timber beam in the TCC construction generates longer spans which also can reduce the floor height if they are used as a flat slab and is preferable in the mid-to-high rise construction [10]. Besides structural and serviceability performance, TCC provides enhanced performance over timber-only floors, including air-borne sound insulation, fire resistance, and thermal mass $[9,11,12]$. Since concrete is more carbonintensive than timber but provides a larger contribution to stiffness and strength on a per unit volume basis, there should be an optimum ratio of concrete and timber in terms of embodied carbon for a specific design. Investigating the various floor parameters that affect this optimum concretetimber ratio is the main goal of this study.

Embodied carbon (EC) is defined as the carbon footprint of a material. It considers the amount of greenhouse gas emissions that is released throughout the supply chain of a material or product, including all extraction, transport, processing, and fabrication activities of a material or product via cradle-to-gate, or cradle-to-site. Cradle-to-gate refers to a partial product life cycle associated with embodied carbon which considers all activities from resource extraction (cradle) to the factory gate (i.e., before it is transported to the consumer). Cradle-to-site extends the cradle-to-gate results to include transportation of the material or product to its site of use [13-15]. Embodied carbon differs from carbon footprint in that embodied carbon can only be associated with materials or products, whereas a carbon footprint could also measure the GHG emissions during the service life of a material, for example, in the operation of a building. Embodied carbon emissions from the building construction sector produce almost $11 \%$ of annual global GHG emissions [16]. Life cycle assessment (LCA) is a method for calculating the environmental impact, be it embodied carbon or total carbon footprint, of a product [17].

Despite the ongoing research in the field of timber structures, most of the timber standards around the globe including North America do not have a standardized method for designing TCC floor systems. Among several proposed methods, the Gamma method based on Annex B of Eurocode 5 [18] is generally used to account for the partial composite action $[9,19]$. The closed-form solution of the Gamma method, commonly used by design engineers, was obtained based on the assumption of sinusoidal distributed load and smeared connection between concrete and timber. Recently, a more general analytical model [20] was developed to predict the load-carrying capacity for ultimate limit state based on potential failure modes [21] and effective bending stiffness for serviceability limit state with loaddeflection response [22] of TCC floor systems with mechanical connectors. This new model does not have the same limiting assumptions on loading and connection as the Gamma method. The Gamma method is most appropriate for systems with stiff mechanical and glued connection but is considered less accurate in the case of flexible connectors [9]. With the assumption of linear-elastic behavior, the Gamma method is not capable of predicting system failure if the system exhibits nonlinear behavior at failure [23].

As the structural integrity of the TCC system primarily depends on interlayer mechanical connectors, analytical models have also been developed for directly calculating the 
strength [24] and stiffness [25] of concrete-to-timber connection based on the component properties. These connection models allow the timber-concrete connection properties, which are required for TCC system design, to be calculated without the need to perform connection tests.

It is common practice in TCC floor design to choose the thickness of the concrete layer based on several requirements of concrete design standard such as anchorage of the fastener, limits for concrete crushing, minimum cover to reinforcement, sound transmission, and a minimum thickness for diaphragm action. Generally, concrete thicknesses of $75 \mathrm{~mm}$ to $100 \mathrm{~mm}$ are used in practice, though past studies have considered thicknesses as low as $30 \mathrm{~mm}$ (plus $20 \mathrm{~mm}$ timber interlayer) with self-tapping screws [26], $50 \mathrm{~mm}$ lightweight concrete with self-tapping screws [26], $57 \mathrm{~mm}$ with inclined self-tapping screws [27], and $48 \mathrm{~mm}$ with notches and dowels using steel fibre reinforcement to remove the cover requirements [28]. Ultrathin toppings of only $12.5 \mathrm{~mm}$ tested by [29] showed significant reductions in both stiffness and strength relative to comparable connections with inclined self-tapping screws in thicker concrete layers. Despite this, the topping was found to be effective in reducing the perception of human-induced vibrations by increasing the natural frequency [29]. Besides, high-strength concrete gives the option to reduce the thickness of the concrete slab in TCC by providing higher load-carrying capacity [30]. However, the stiffness of connectors in highstrength concrete is usually lower compared to normal weight concrete [31].

Research has shown that suitable indicators of human response to floor vibration are the fundamental natural frequency of the floor and the deflection of the floor under a concentrated load at the center of the floor $[9,19]$. Hamm et al. [32] proposed a method for checking the vibration performance of TCC floors based on the natural frequency and static deflection under $2 \mathrm{kN}$ load at the floor center. Hu et al. [33] proposed a vibration criterion for TCC floors based on the natural frequency and static deflection under $1 \mathrm{kN}$ load at the floor center. From their study, vibration control span can also be calculated directly from the effective bending stiffness and mass per unit length of a $1 \mathrm{~m}$ wide strip TCC beam. Besides, CSA O86 [34] provides a vibration-based limitation on the allowable span for CLT floors, without accounting for potential composite behavior adequately. A previous study [35] investigated the embodied carbon of the TCC system with CLT up to 7 ply using the Gamma method [18] and satisfying the vibration criterion proposed by Hamm et al. [32] for floor spans. The study concluded that lower embodied carbon values can be found by using thicker CLT panels rather than adding the concrete topping. Also, the influence of the connector properties on the TCC design requirement was found to be limited beyond a moderate degree of composite action. In this study, the sustainability aspects of the TCC system are investigated by using a more detailed TCC design method with all possible thicknesses of CLT (up to 9 ply) and glued laminated timber (GLT). The vibration criterion proposed by $\mathrm{Hu}$ et al. [33] is used in the development of floor spans along with satisfying other structural, serviceability, and acoustic performance requirements.

\section{Methodology}

As stated above, the goal of this study is to investigate the impacts on design selection with respect to the main TCC floor components, namely, concrete and timber, for specific span requirements on the embodied carbon of the system. The allowable span for a TCC floor system can be developed by considering all ultimate limit states related to timber, concrete, and shear connectors, and serviceability limit states related to deflection and vibration. The ultimate and serviceability limit state requirements for TCC floors with different combinations of materials, dimensions, and connection characteristics were evaluated based on [20]. Although long-term behavior of TCC systems such as creep deflection may be critical, this was not considered since it will be shown later that short-term serviceability criteria, such as vibration, tend to govern the design $[19,33]$.

2.1. Ultimate Limit State. In ultimate limit states, a floor system might fail due to concrete crushing, timber crushing, or screw yielding, when the stress demand exceeds the capacity at concrete layer, timber layer, and shear connectors, respectively. The lowest capacity associated with these failure modes would govern the allowable floor span. In the developed analytical model [21, 22], the MTPC composite beam is divided into two subsystems under uniformly distributed load. In the first subsystem (subsystem 1), the connection is released and the deflection of the unconnected beam under an applied load is calculated. In the second subsystem (subsystem 2), the connectors are replaced by redundant shear force. According to [21], the slip at the interlayer of subsystem 1 and subsystem 2 can be calculated as follows:

$$
\begin{aligned}
& \omega_{1,0}=\frac{w_{r}\left(h_{c}+h_{i}+h_{t}\right)\left(3 L^{2} n_{r}-n_{r}^{3}\right)}{96\left(E_{c} I_{c}+E_{t} I_{t}\right)}, \\
& \omega_{1,1}=\left[\frac{\left(E_{c} A_{c}+E_{t} A_{t}\right)}{E_{c} A_{c} E_{t} A_{t}}+\frac{\left(h_{c}+h_{t}+2 h_{i}\right)\left(h_{c}+h_{t}\right)}{4\left(E_{c} I_{c}+E_{t} I_{t}\right)}\right] \cdot \frac{n_{r}}{2} .
\end{aligned}
$$

Here, $L$ is the span, $w$ is the uniformly distributed load, and $n_{i}$ refers to the distance of each symmetrical screw row from midspan. The primary material and geometric parameters are specified as follows; $h$ : depth, $A$ : cross-sectional area, $I$ : moment of inertia, $E$ : modulus of elasticity, and $b$ : width of the cross section of concrete slab, insulation, and MTP with the subscripts $c, i$, and $t$ respectively.

By applying the displacement compatibility condition at the interface, the redundant shear force in the connectors with $r$ number of connector rows along the span can be obtained based on the following matrix expression [21] as 


$$
\begin{aligned}
& \left\{\begin{array}{c}
\omega_{1,0} \\
\omega_{2,0} \\
\vdots \\
\omega_{r, 0}
\end{array}\right\}+\left[\left(\begin{array}{cccc}
\omega_{1,1} & \omega_{1,2} & \ldots & \omega_{1, r} \\
\omega_{2,1} & \omega_{2,2} & \ldots & \omega_{2, r} \\
\vdots & \vdots & \ddots & \vdots \\
\omega_{r, 1} & \omega_{r, 2} & \ldots & \omega_{r, r}
\end{array}\right)+\left(\begin{array}{cccc}
f & 0 & \ldots & 0 \\
0 & f & \ldots & 0 \\
\vdots & \vdots & \ddots & \vdots \\
0 & 0 & \ldots & f
\end{array}\right)\right] \\
& \left\{\begin{array}{c}
X_{1} \\
X_{2} \\
\vdots \\
X_{r}
\end{array}\right\}=0 .
\end{aligned}
$$

Here, $f=1 / k$ is the flexibility of the connection and $k$ is the stiffness of the shear connector.

Then, the superposition method can be implemented to determine the vertical deflection [22] as follows:

$$
\Delta_{r}=\frac{5 w_{r} L^{4}-19.2 X_{r}\left(h_{c}+h_{t}+2 h_{i}\right)\left(2 L-n_{r}\right) n_{r}}{384\left(E_{c} I_{c}+E_{t} I_{t}\right)} .
$$

Here, $r$ is the number of connector rows along the span and $X_{r}$ is the sum of shear forces in all the connectors between the midspan and the panel edge, which is equal to the resultant normal force at a given cross section.

The linear-elastic effective bending stiffness [22] of the MTPC composite system can then be written as

$$
E I_{\mathrm{eff}}=\frac{5 w_{1} L^{4}}{384 \Delta_{1}}
$$

After yielding of each connector, the stresses in concrete and timber are checked to determine if either of them fails (e.g., concrete compression, timber tension, and/or shear) before yielding of the next connector.

According to [21], the axial stress in the members can be written as

$$
\begin{aligned}
\sigma_{t, N} & =\frac{\sum_{i=1}^{n} X_{i}}{A_{t}}, \\
\sigma_{c, N} & =\frac{\sum_{i=1}^{n} X_{i}}{A_{c}} .
\end{aligned}
$$

And the bending stress in the members of each subsystem can be written as

$$
\begin{aligned}
\sigma_{1, t}= & \frac{M_{t}}{S_{t}}, \\
\sigma_{1, c}= & \frac{M_{c}}{S_{c}}, \\
\sigma_{2, t}= & \frac{\sum_{i=1}^{n} X_{i}\left(\left(h_{c}+h_{t}+2 h_{i}\right) / 2 \cdot E_{t} I_{t} /\left(E_{c} I_{c}+E_{t} I_{t}\right)\right)}{S_{t}}, \\
\sigma_{2, c}= & \frac{\sum_{i=1}^{n} X_{i}\left(\left(h_{c}+h_{t}+2 h_{i}\right) / 2 \cdot E_{c} I_{c} /\left(E_{c} I_{c}+E_{t} I_{t}\right)\right)}{S_{c}} .
\end{aligned}
$$

Here, $M_{t}$ and $M_{c}$ are the bending moment and $S_{t}$ and $S_{c}$ are the section modulus of timber and concrete, respectively. Therefore, the resultant axial stress in the members due to bending at the position of cross section is as follows:

$$
\begin{aligned}
& \sigma_{t, B}=\sigma_{1, t}+\sigma_{2, t}, \\
& \sigma_{c, B}=\sigma_{1, c}+\sigma_{2, c} .
\end{aligned}
$$

The stress distributions of the subsystems and the actual system are shown in Figure 2.

The extreme fibre stress of timber must not be greater than its factored bending strength as follows:

$$
\sigma_{t, B / t}+\sigma_{t, N} \leq f_{b}
$$

Here, $f_{b}$ is the specified bending strength of the timber. The shear stress in timber member can be calculated as follows:

$$
\tau_{\max }=\frac{y_{t}^{2} E_{t} V}{2 E I_{\text {eff }}}<f_{v}, \quad \text { with, } y_{t}=\frac{h_{t}\left(\sigma_{t, N}+\sigma_{t, B}\right)}{2 \sigma_{t, B}} .
$$

Here, $V$ is the applied shear force at the connector location due to the external load, $y_{t}$ is the distance of the neutral axis of timber to the tension edge, and $f_{v}$ is the specified shear strength of timber (rolling shear for CLT).

The top extreme fibre stress of concrete in compression must not be greater than its factored compressive strength and the bottom extreme fibre stress of concrete in tension must not be greater than its factored modulus of rupture as follows:

$$
\begin{aligned}
& \sigma_{c, c} \leq f_{c}^{\prime}, \\
& \sigma_{c, t} \leq\left(0.6 \lambda \sqrt{f_{c}^{\prime}}\right) .
\end{aligned}
$$

Here, $f_{c}^{\prime}$ is the concrete specified compressive strength and $\lambda$ is the modification factor for concrete density.

\subsection{Serviceability Limit State}

2.2.1. Vibration. Hu et al. [36] presented the following equation for the vibration-controlled span of TCC floors:

$$
L \leq \frac{\left((E I)_{\mathrm{eff}}^{1 m}\right)^{0.278}}{4.835 m_{L}^{0.166}}
$$

where $m_{L}$ is mass per unit length of $1 \mathrm{~m}$ wide strip of TCC beam $(\mathrm{kg} / \mathrm{m}), L$ is the span $(\mathrm{m})$, and $E I_{\text {eff }}$ is the effective bending stiffness of the floor $\left(\mathrm{Nm}^{2}\right)$.

2.2.2. Deflection. The deflection can be calculated based on the load combination associated with serviceability limit state in CSA O86 [34]. The deflection under the specified load is required to be within the limit of L/180 and can be calculated as follows:

$$
\Delta=\frac{5 w L^{4}}{384 E I_{\mathrm{eff}}},
$$

where $w$ is the uniformly distributed load $(\mathrm{N} / \mathrm{m})$. 


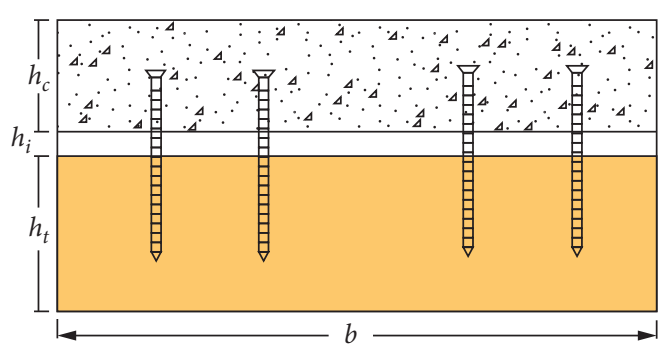

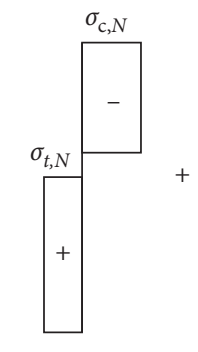

Axial stress (subsystem 2)

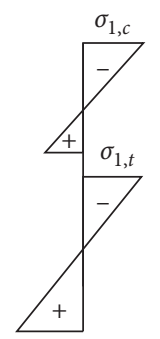

Bending stress (subsystem 1)

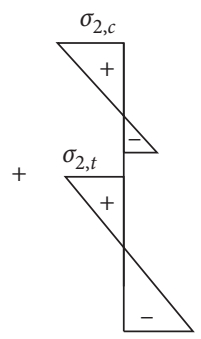

Bending stress (subsystem 2)

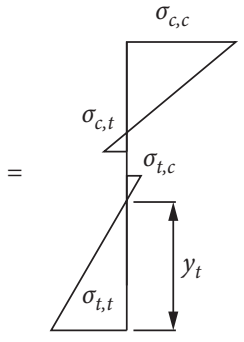

Total stress

Figure 2: Stress distributions in the TCC system.

2.2.3. Acoustic Requirements. As required by the NBCC [37], the levels of noise or sound control should be adequate in a building. Sound transmission class (STC) is the main parameter to evaluate the acoustic performance of floor assemblies. Nonetheless, the determination of the exact STC of a floor is still of great difficulty using the modelling techniques, while a laboratory test is considered the most accurate way. Schmid [38] proposes a mathematical model for the estimation of the air-borne sound level which is consistent with STC. According to [38], within the area mass density range of $30 \mathrm{~kg} / \mathrm{m}^{2}$ to $800 \mathrm{~kg} / \mathrm{m}^{2}$, the mass law is practically applicable to the influence of the subfloor and concrete as follows:

$$
\mathrm{STC}=20 \log (m)+7 \mathrm{~dB},
$$

where $m$ is the total mass per unit area $\left(\mathrm{kg} / \mathrm{m}^{2}\right)$.

Based on the described methodology, the allowable spans were developed for a variety of TCC floor systems built with MTP (as in Figure 3), satisfying all the requirements stated earlier. The geometric and mechanical properties used in the design to develop the span table of TCC with MTP are presented in Table 1. Normal weight concrete of $35 \mathrm{MPa}$ compressive strength at 28 days was assumed with a modulus of elasticity of $26600 \mathrm{MPa}$ and density of $2300 \mathrm{~kg} / \mathrm{m}^{3}$. GLT made of No. 2 grade SprucePine-Fir (S-P-F) lumber and E1 grade CLT made of 1950Fb-1.7E grade S-P-F lumber in longitudinal and No. 3/ Stud S-P-F lumber in transverse layer were considered in the calculation for a width of $1 \mathrm{~m}$, according to CSA O86 [34]. The density of lumber was $420 \mathrm{~kg} / \mathrm{m}^{3}$. The connector was fully threaded self-tapping screw of $11 \mathrm{~mm}$ diameter with a $45^{\circ}$ insertion angle to timber grain and $100 \mathrm{~mm}$ penetration length. The connection stiffness and strength were calculated based on $[24,25]$, respectively, and are presented in Table 2. As required by the National Building Code of Canada (NBCC) [37], the appropriate load combinations were considered. The dead loads were obtained from the self-weight of the members and an additional superimposed load of $1 \mathrm{kPa}$ while a live load of $2.4 \mathrm{kPa}$ was considered for commercial occupancy.

The MATLAB software was used to perform repetitive calculations, based on the analytical equations presented in $[21,22]$. The allowable span for a particular combination of floor parameters was obtained based on the shortest span that meets all structural and serviceability limit states.
Table 3 presents the allowable spans of TCC floors when all appropriate design criteria are considered. It was found that all floor spans were governed by vibration for the stated applied load combinations, which generally agrees with the common practice [35]. In Table 3, the spacing of the connector was $250 \mathrm{~mm}$ along the span. The analysis was repeated for different MTP thicknesses as shown in Table 3. TCC systems with concrete thicknesses of 50,75 , and $100 \mathrm{~mm}$ for each MTP are included in Table 3 . Here, $50 \mathrm{~mm}$ represents a practical lower bound and $100 \mathrm{~mm}$ is a typical upper bound found in practice. STC values for the floor configurations are also presented in Table 3. Based on this, the influence of the thickness of concrete on TCC effective bending stiffness, allowable floor span, and design decision for TCC through optimizing vibration and STC requirements are discussed below.

Table 3 also reports the embodied carbon content of each case study per square meter $\left(\mathrm{kgCO}_{2} \mathrm{eq} / \mathrm{m}^{2}\right)$ obtained from the LCA analysis using Athena Impact Estimator for Buildings [40] by considering concrete and timber elements only. Here, the cost or other environmental impacts from the material selection, for example, eutrophication or acidification potential and on-site construction are not accounted. For the purposes of this study, the commercial buildings were assumed to be located in Vancouver, Canada, as there are benchmarks for energy and emissions within various locations. To focus exclusively on near term embodied emissions, carbon storage in the timber material was excluded $[41,42]$. The carbon intensity of the CLT from Athena was compared with available environmental product declaration values from major CLT producers in Canada $[43,44]$ and was found to overestimate the intensity by $15-30 \%$. This implies that the results are shifted upwards slightly; however, that difference does not change the general conclusions. Based on this life-cycle analysis, the design decision for TCC through optimizing embodied carbon is discussed below.

\section{Results and Discussion}

3.1. Influence of MTP Thickness on TCC Bending Stiffness. In the TCC system, generally, effective bending stiffness and mass per unit area dictate the performance of the composite floor system. From Table 3, it can be seen that the effective bending stiffness of the TCC system increases marginally 


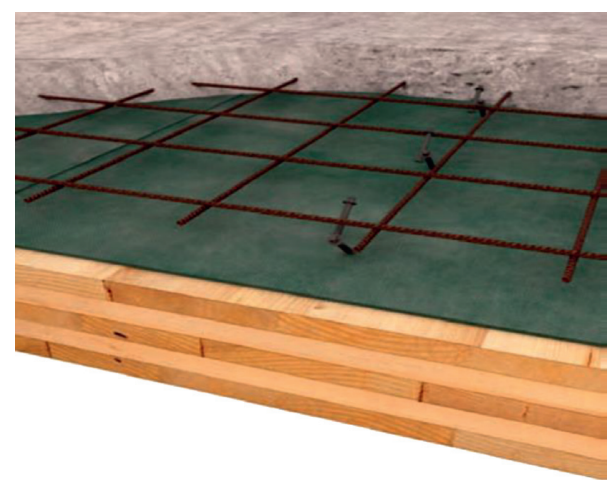

FIgure 3: Type of TCC system with MTP and inclined self-tapping screws [39].

TABle 1: Design properties of the concrete and MTP.

\begin{tabular}{lccccc}
\hline & Thickness $(\mathrm{mm})$ & Modulus of elasticity $(\mathrm{MPa})$ & Bending strength $(\mathrm{MPa})$ & Shear strength $(\mathrm{MPa})$ & Compressive strength $(\mathrm{MPa})$ \\
\hline Concrete & $50,75,100$ & 26600 & - & - & 35 \\
GLT & $89,140,186$ & 9500 & 11.8 & 1.3 & - \\
CLT & $105,175,245,315$ & 11281 & 28.2 & 0.5 & - \\
\hline
\end{tabular}

TABLE 2: Properties of the self-tapping screw.

\begin{tabular}{cccc}
\hline MTP & $\begin{array}{c}\text { Acoustic layer } \\
(\mathrm{mm})\end{array}$ & $\begin{array}{c}\text { Stiffness } \\
(\mathrm{kN} / \mathrm{mm} / \mathrm{screw})\end{array}$ & $\begin{array}{c}\text { Yield strength } \\
(\mathrm{kN} / \mathrm{screw})\end{array}$ \\
\hline GLT & 0 & 15.24 & 15.34 \\
CLT & 0 & 14.00 & 16.19 \\
GLT & 5 & 7.34 & 14.66 \\
CLT & 5 & 7.03 & 15.51 \\
\hline
\end{tabular}

with the increase of concrete thickness but increases exponentially with the increase of timber thickness. From Figure 4, the timber thickness has a dominant effect on the effective bending stiffness of the TCC system compared to the thickness of concrete. Doubling the depth of concrete seems to make little difference to the stiffness but doubling the timber depth has a significant impact.

3.2. Influence of Concrete Thickness on TCC Floor Span. It is also noted that mass per unit area is influenced largely by concrete thickness because of the higher density of concrete $\left(2300 \mathrm{~kg} / \mathrm{m}^{3}\right)$ compared to timber $\left(420 \mathrm{~kg} / \mathrm{m}^{3}\right)$ and the system deflection decreases with the increase of concrete thickness. Therefore, the effective bending stiffness increases with a thicker MTP, but the total mass per unit area only increases marginally which yields a larger floor span. From Figure 5, it can also be seen that after a certain MTP thickness (approximately $150 \mathrm{~mm}$ ), the added concrete thickness has minor and, in some case, a negative impact on the span length while, for MTP with thicknesses less than $150 \mathrm{~mm}$, the span length increases with the increase of concrete thickness. Therefore, it can be concluded that, for TCC span longer than $7 \mathrm{~m}$, the MTP thickness should be larger than $150 \mathrm{~mm}$ while keeping the concrete thickness within the range of $50-75 \mathrm{~mm}$. Besides, for allowable TCC spans smaller than $7 \mathrm{~m}$, a concrete thickness range of $75-100 \mathrm{~mm}$ is required if thinner MTP is selected.

3.3. Design Decision Based on Vibration Performance. The design of all the TCC floors was governed by the vibration criteria, which generally agrees with the common practice. In addition to changing the properties of the floor, the addition of concrete to the TCC floor increases the weight significantly because of the higher density of concrete compared to timber, which can subsequently create a demand for larger framing members and foundations due to an increase in dead and consequently seismic loads. The influence of the weight of TCC is similar to the influence of concrete thickness on the allowable span. Therefore, an increase in concrete thickness tends to reduce the allowable floor span due to a reduction in natural frequency which is detrimental to vibration performance.

3.4. Design Decision Based on Connector Properties. In the developed span Table 3, all possible MTP and concrete thicknesses were investigated with constant connection properties at $250 \mathrm{~mm}$ spacings and without an acoustic layer. A parallel span table was also developed for different connector properties as presented in Table 4, by adding $500 \mathrm{~mm}$ screw spacings, $5 \mathrm{~mm}$ of acoustic layer, and associated STC values for each span. It was found that there is a minimal benefit in increasing the stiffness of connection beyond a moderate threshold by adjusting the connection parameters such as connector spacings because the impact in effective bending stiffness is small. It was also found that, by doubling the number of connectors, the TCC floor span only increases by approximately $250 \mathrm{~mm}$. Further, as the TCC designs were governed by stiffness-related design parameters, the yield strength of the connection was similarly not influential in the design outcome. Together these results indicate that the 
TABLE 3: TCC allowable floor spans with associated embodied carbon for $250 \mathrm{~mm}$ spaced connectors.

\begin{tabular}{|c|c|c|c|c|c|c|c|c|}
\hline \multirow[b]{2}{*}{ MTP } & \multirow{2}{*}{$\begin{array}{l}\text { MTP thickness } \\
\quad(\mathrm{mm})\end{array}$} & \multirow{2}{*}{$\begin{array}{l}\text { Concrete thickness } \\
\qquad(\mathrm{mm})\end{array}$} & \multirow{2}{*}{$\begin{array}{l}\text { Effective stiffness }\left(\left(10^{6}\right)\right. \\
\left.\qquad \mathrm{Nm}^{2}\right)\end{array}$} & \multirow{2}{*}{$\begin{array}{c}\text { Span } \\
(\mathrm{m})\end{array}$} & \multirow{2}{*}{$\begin{array}{l}\text { STC } \\
(\mathrm{dB})\end{array}$} & \multicolumn{3}{|c|}{ Embodied carbon $\left(\mathrm{kgCO}_{2} / \mathrm{m}^{2} \mathrm{eq}\right)$} \\
\hline & & & & & & Total & $\begin{array}{l}\text { Timber } \\
\text { share }\end{array}$ & $\begin{array}{c}\text { Reinforced concrete } \\
\text { share }\end{array}$ \\
\hline \multirow{12}{*}{ GLT } & \multirow{4}{*}{89} & 0 & 0.08 & 2.62 & 39 & 15.4 & \multirow{4}{*}{15.4} & 0.0 \\
\hline & & 50 & 1.87 & 4.98 & 49 & 39.0 & & 23.6 \\
\hline & & 75 & 3.03 & 5.39 & 52 & 51.3 & & 35.9 \\
\hline & & 100 & 4.9 & 5.92 & 55 & 62.6 & & 47.2 \\
\hline & \multirow{4}{*}{140} & 0 & 0.61 & 4.26 & 42 & 23.0 & \multirow{4}{*}{23.0} & 0.0 \\
\hline & & 50 & 4.61 & 6.26 & 49 & 46.6 & & 23.6 \\
\hline & & 75 & 6.07 & 6.44 & 52 & 58.9 & & 35.9 \\
\hline & & 100 & 8.22 & 6.75 & 55 & 70.2 & & 47.2 \\
\hline & \multirow{4}{*}{186} & 0 & 2.09 & 5.73 & 45 & 29.7 & \multirow{4}{*}{29.7} & 0.0 \\
\hline & & 50 & 8.91 & 7.39 & 49 & 53.3 & & 23.6 \\
\hline & & 75 & 10.65 & 7.43 & 52 & 65.6 & & 35.9 \\
\hline & & 100 & 13.06 & 7.60 & 55 & 76.9 & & 47.2 \\
\hline \multirow{16}{*}{ CLT } & \multirow{5}{*}{105 (3 ply) } & 0 & 0.34 & 3.80 & 40 & 11.9 & \multirow{4}{*}{11.9} & 0.0 \\
\hline & & 50 & 2.7 & 5.47 & 49 & 35.5 & & 23.6 \\
\hline & & 75 & 3.94 & 5.78 & 52 & 47.8 & & 35.9 \\
\hline & & 100 & 5.88 & 6.21 & 55 & 59.1 & & 47.2 \\
\hline & & 0 & 1.73 & 5.50 & 44 & 18.2 & \multirow{4}{*}{18.2} & 0.0 \\
\hline & \multirow{3}{*}{175 (5 ply) } & 50 & 8.41 & 7.29 & 49 & 41.8 & & 23.6 \\
\hline & & 75 & 10.04 & 7.33 & 52 & 54.1 & & 35.9 \\
\hline & & 100 & 12.35 & 7.50 & 55 & 65.5 & & 47.2 \\
\hline & \multirow{4}{*}{245 (7 ply) } & 0 & 4.75 & 6.88 & 47 & 24.6 & \multirow{4}{*}{24.6} & 0.0 \\
\hline & & 50 & 19.65 & 9.01 & 49 & 48.2 & & 23.6 \\
\hline & & 75 & 21.73 & 8.92 & 52 & 60.5 & & 35.9 \\
\hline & & 100 & 24.43 & 8.93 & 55 & 71.8 & & 47.2 \\
\hline & \multirow{4}{*}{315 (9 ply) } & 0 & 10.2 & 8.16 & 49 & 31.0 & \multirow{4}{*}{31.0} & 0.0 \\
\hline & & 50 & 38.35 & 10.63 & 49 & 54.6 & & 23.6 \\
\hline & & 75 & 40.94 & 10.46 & 52 & 66.9 & & 35.9 \\
\hline & & 100 & 44.07 & 10.37 & 55 & 78.2 & & 47.2 \\
\hline
\end{tabular}

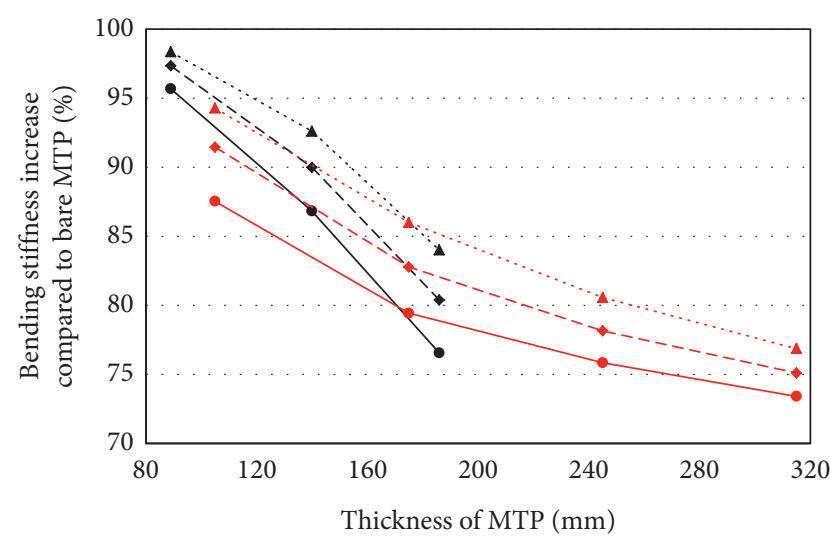

$$
\begin{array}{ll}
\rightarrow-\text { GLT_concrete-50 } & \rightarrow \text { CLT_concrete-50 } \\
-\bullet \text { GLT_concrete-75 } & -\bullet \text { CLT_concrete-75 } \\
\cdots \text { •. GLT_concrete-100 } & \cdots \text {... CLT_concrete-100 }
\end{array}
$$

FIGURE 4: Effective bending stiffness increase compared to bare MTP versus thickness of MTP in TCC system.

choice of connection between the timber and concrete elements has only a minor impact on the design beyond a threshold level (moderately partial composite) [35] and the thickness of concrete required for acceptable vibration

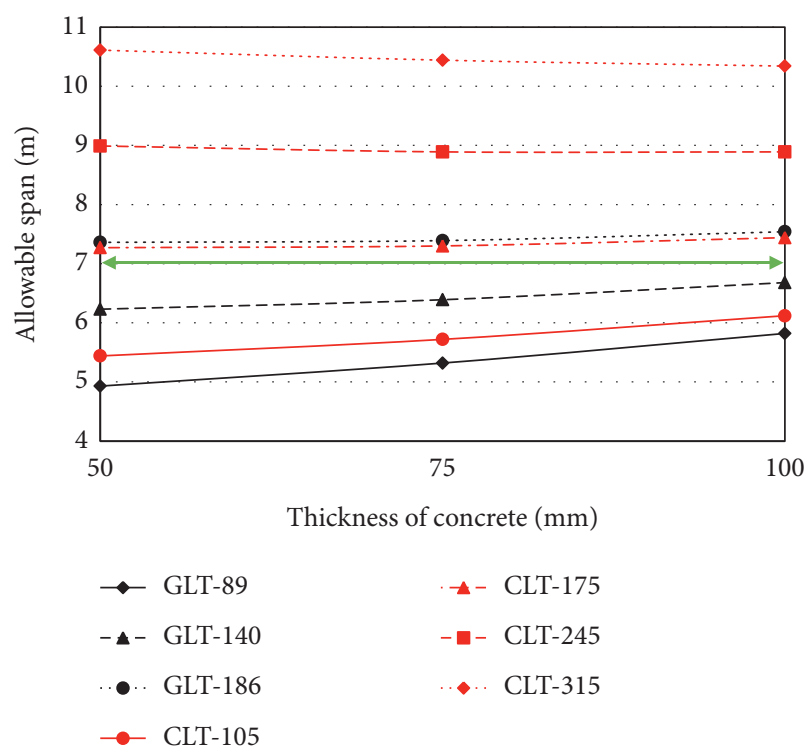

FIGURE 5: Allowable span versus thickness of concrete in TCC system.

performance for a given span and timber element is more strongly determined by the anchorage requirements of the connectors. 
TABLE 4: Influence of connection properties on TCC floor allowable spans.

\begin{tabular}{|c|c|c|c|c|c|c|c|c|}
\hline \multirow{3}{*}{ Timber } & \multirow{3}{*}{$\begin{array}{c}\text { Timber thickness } \\
(\mathrm{mm})\end{array}$} & \multirow{3}{*}{$\begin{array}{l}\text { Insulation thickness } \\
\qquad(\mathrm{mm})\end{array}$} & \multicolumn{6}{|c|}{ Concrete thickness $(\mathrm{mm})$} \\
\hline & & & \multicolumn{6}{|c|}{ Connector spacing $(\mathrm{mm})$} \\
\hline & & & 250 & 500 & 250 & 500 & 250 & 500 \\
\hline \multirow{6}{*}{ GLT } & 89 & 0 & $4.98(+)$ & $4.75(+)$ & $5.39(++)$ & $5.16(++)$ & $5.92(+++)$ & $5.71(+++)$ \\
\hline & 89 & 5 & $4.76(+++)$ & $4.54(+++)$ & $5.14(+++)$ & $4.93(+++)$ & $5.67(+++)$ & $5.48(+++)$ \\
\hline & 140 & 0 & $6.26(+)$ & $6.00(+)$ & $6.44(++)$ & $6.15(++)$ & $6.75(+++)$ & $6.46(+++)$ \\
\hline & 140 & 5 & $5.97(+++)$ & $5.75(+++)$ & $6.10(+++)$ & $5.87(+++)$ & $6.40(+++)$ & $6.17(+++)$ \\
\hline & 186 & 0 & $7.39(+)$ & $7.13(+)$ & $7.43(++)$ & $7.13(++)$ & $7.60(+++)$ & $7.28(+++)$ \\
\hline & 186 & 5 & $7.07(+++)$ & $6.86(+++)$ & $7.06(+++)$ & $6.83(+++)$ & $7.20(+++)$ & $6.96(+++)$ \\
\hline \multirow{8}{*}{ CLT } & 105 & 0 & $5.47(+)$ & $5.23(+)$ & $5.78(++)$ & $5.52(++)$ & $6.21(+++)$ & $5.95(+++)$ \\
\hline & 105 & 5 & $5.23(+++)$ & $5.02(+++)$ & $5.50(+++)$ & $5.28(+++)$ & $5.93(+++)$ & $5.72(+++)$ \\
\hline & 175 & 0 & $7.29(+)$ & $7.05(+)$ & $7.33(++)$ & $7.05(++)$ & $7.50(+++)$ & $7.20(+++)$ \\
\hline & 175 & 5 & $7.02(+++)$ & $6.82(+++)$ & $7.01(+++)$ & $6.79(+++)$ & $7.15(+++)$ & $6.92(+++)$ \\
\hline & 245 & 0 & $9.01(+)$ & $8.78(+)$ & $8.92(++)$ & $8.64(++)$ & $8.93(+++)$ & $8.62(+++)$ \\
\hline & 245 & 5 & $8.74(+++)$ & $8.56(+++)$ & $8.59(+++)$ & $8.39(+++)$ & $8.56(+++)$ & $8.35(+++)$ \\
\hline & 315 & 0 & $10.63(+)$ & $10.41(+)$ & $10.46(++)$ & $10.20(++)$ & $10.37(+++)$ & $10.08(+++)$ \\
\hline & 315 & 5 & $10.36(+++)$ & $10.20(+++)$ & $10.14(+++)$ & $9.96(+++)$ & $10.02(+++)$ & $9.82(+++)$ \\
\hline
\end{tabular}

Remarks: "+" represents the STC is the first level of the acoustic performance or at least $45 \mathrm{~dB}$. "++" represents the STC is the second level of the acoustic performance or at least $50 \mathrm{~dB}$. "+++" represents the STC is the third level of the acoustic performance or at least $55 \mathrm{~dB}$.

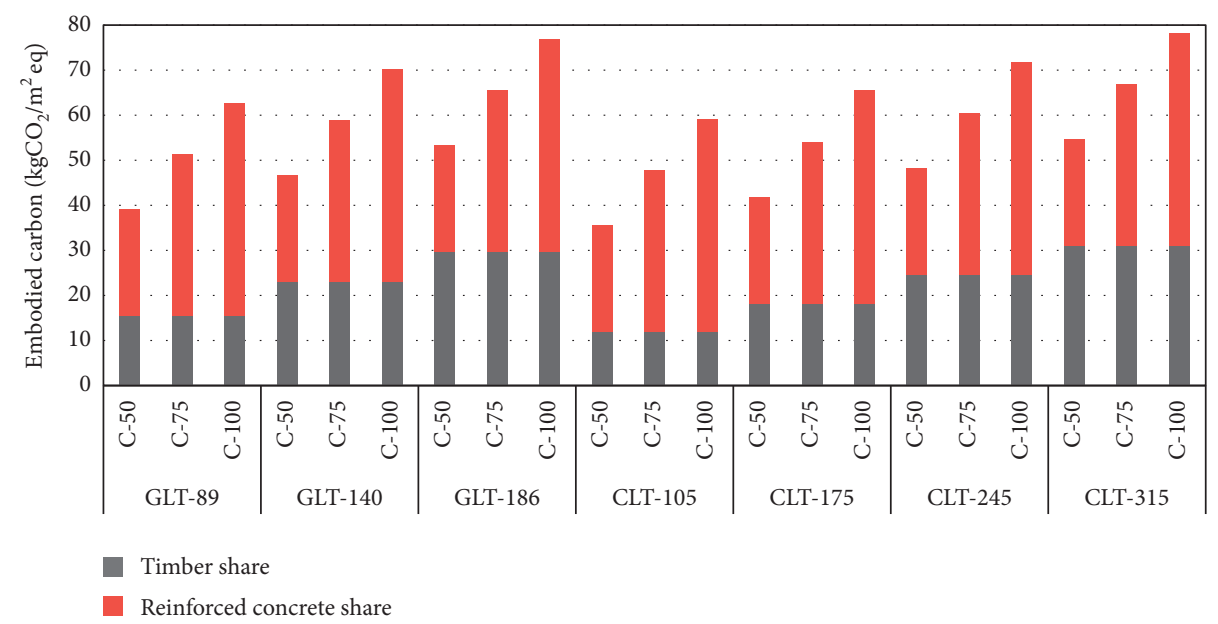

FIgURE 6: Embodied carbon versus thickness of concrete and MTP in TCC system.

3.5. Design Decision Based on Acoustic Performance. The sound transmission class value for each span is also presented in Table 4 along with the span for an additional $5 \mathrm{~mm}$ acoustic layer. Although an increase in concrete thickness can improve the acoustic performance of the composite floor, as stated above, the addition of concrete may cause a reduction in allowable span due to vibration requirements. To mitigate this issue, an acoustic layer can be placed between MTP and concrete, which will enhance sound insulation without a potential negative impact on vibrationcontrolled floor span. It was found that, by providing a $5 \mathrm{~mm}$ acoustic layer, the TCC floor span only reduces by only approximately $300 \mathrm{~mm}$. Therefore, acoustic layers can provide designers with a chance to achieve higher STC values and nearly similar spans (compromising around $300 \mathrm{~mm}$ ) without increasing the concrete thickness and therefore embodied carbon for sustainable design.
3.6. Design Decision Based on Embodied Carbon. The embodied carbon will obviously increase once concrete topping is added to MTP to form TCC. Figure 6 shows how the increase in timber and concrete thickness can lead to an increase in embodied carbon based on the share of timber and reinforced concrete. For each MTP type, the largest increase in embodied carbon happens when a $50 \mathrm{~mm}$ thick concrete topping is added to bare MTP. Thereafter, the rate of increase in embodied carbon decreases as the concrete thickness increases by $25 \mathrm{~mm}$ increment to a total of $100 \mathrm{~mm}$. Figure 7 was plotted to assist designers in the selection of TCC system by taking into consideration the amount of embodied carbon for specific span requirements. For instance, for a span length of $6 \mathrm{~m}$, a design engineer has options of CLT-105_Concrete-100 (105 mm thick CLT with $100 \mathrm{~mm}$ thick concrete) and GLT-140_Concrete-50. Comparing their embodied carbon content per square meter, the 


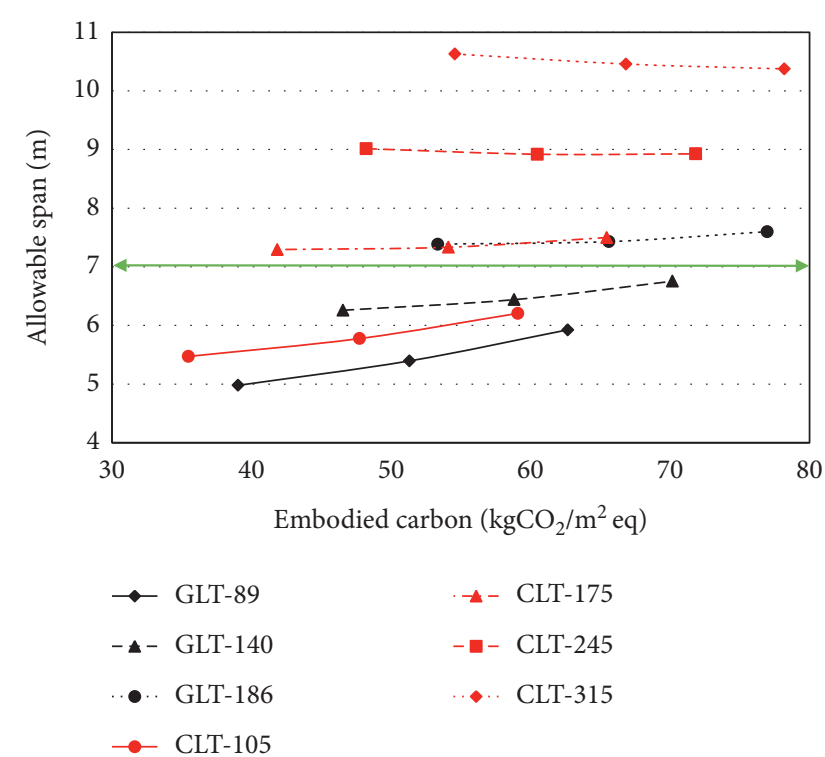

Figure 7: Allowable span versus embodied carbon of TCC system (the three points on each curve represent from left to right $50 \mathrm{~mm}$, $75 \mathrm{~mm}$, and $100 \mathrm{~mm}$ thick concrete).

GLT-140_Concrete-50 is more environmentally friendly, comparing to the other option. Similarly, one can observe that two systems, GLT-186_Concrete-75 and CLT175_Concrete-100, provide almost identical spans and embodied carbon and the same applies to GLT-186_Concrete-50 and CLT-175_Concrete-75. Based on these observations, it is generally beneficial from a sustainability perspective to increase the thickness of MTP in an attempt to reach a longer span than to increase concrete thickness.

\section{Conclusions}

By using a new analysis approach [20] to investigate the influence of concrete topping on the structural and sustainability performance of the TCC system, the following conclusions can be drawn:

(1) The increase in concrete thickness to achieve a longer span is only effective for TCC floor systems with spans shorter than about $7 \mathrm{~m}$, due to vibration performance being the controlling design parameter. This is because the addition of concrete beyond this span has the counteracting effect of increasing bending stiffness but reducing the natural frequency.

(2) Following from 1 above, it is generally true that it is beneficial to increase MTP thickness instead of concrete thickness to achieve a longer span, especially for a floor span shorter than $7 \mathrm{~m}$, from a sustainability perspective. This is due to the substantially larger carbon footprint of concrete than timber on a per-volume basis.

(3) If self-tapping screws are used, there is evidence to suggest that the connection parameters, such as spacing, have a minor influence on the allowable floor span when these parameters are above certain threshold levels. Other connector systems may provide more sensitivity, but further studies are required.

This research focused on embodied carbon as a single metric and did not account for cost or other environmental impacts from the material selection, for example, eutrophication or acidification potential and on-site construction. Further analysis including these effects and accounting for the relationship between embodied carbon and life cycle cost is recommended.

\section{Data Availability}

All the data, models, and code generated or used during the study appear in the submitted article.

\section{Conflicts of Interest}

The authors declare that they have no conflicts of interest.

\section{Acknowledgments}

The authors would like to thank the Natural Sciences and Engineering Research Council of Canada (NSERC) for the financial support through the Industrial Research Chair (IRC) in Engineered Wood and Building System Program.

\section{References}

[1] A. Gosselin, P. Blanchet, N. Lehoux, and Y. Cimon, "Main motivations and barriers for using wood in multi-story and non-residential construction projects," BioResources, vol. 12, no. 1, pp. 546-570, 2017.

[2] R. F. Falk, "Wood as a sustainable building material," Forest Products Journal, vol. 59, no. 9, pp. 6-12, 2009.

[3] L. F. Cabeza, C. Barreneche, L. Miró, J. M. Morera, E. Bartolí, and A. Inés Fernández, "Low carbon and low embodied energy materials in buildings: a review," Renewable and Sustainable Energy Reviews, vol. 23, pp. 536-542, 2013.

[4] H. Reid, S. Huq, A. Inkinen et al., Using Wood Products to Mitigate Climate Change: A Review of Evidence and Key Issues for Sustainable Development, International Institute for Environment and Development, Scotland, UK, 2004.

[5] P. Kremor and M. Symmons, "Mass-timber construction as an alternative to concrete and steel in the Australian building industry: a PESTL evaluation of the potential," International Wood Products Journal, vol. 6, no. 3, pp. 138-147, 2015.

[6] D. Yeoh, M. Fragiacomo, M. De Franceschi, and K. Heng Boon, "State of the art on timber-concrete composite structures: literature review," Journal of Structural Engineering, vol. 137, no. 10, pp. 1085-1095, 2011.

[7] M. A. H. Mirdad and Y. H. Chui, "Behaviour of mass timber panel-concrete connections with inclined self-tapping screws and insulation layer," in Proceedings of the World Conference on Timber Engineering (WCTE), Seoul, Republic of Korea, August 2018.

[8] F. Moar, S. Vanzo, M. A. H. Mirdad, Y. H. Chui, and Y. Steige, "Influence of self-tapping screw inclination and soundproofing resilient interlayer on timber-concrete composite slab," in Proceedings of the 5th International Conference on Structural Health Assessment of Timber Structures, Guimarães, Portugal, 2019. 
[9] A. Dias, J. Schänzlin, and P. Dietsch, "Design of timberconcrete composite structures," Action FP1402/WG 4, COST, European Cooperation in Science and Technology, Aachen, Germany, 2018.

[10] M. A. H. Mirdad and Y. H. Chui, "Load-slip performance of Mass Timber Panel-Concrete (MTPC) composite connection with self-tapping screws and insulation layer," Construction and Building Materials, vol. 213, pp. 696-708, 2019.

[11] A. Ceccotti, "Composite concrete-timber structures," Progress in Structural Engineering and Materials, vol. 4, no. 3, pp. 264-275, 2002.

[12] A. Dias, J. Skinner, K. Crews, and T. Tannert, "Timberconcrete-composites increasing the use of timber in construction," European Journal of Wood and Wood Products, vol. 74, no. 3, pp. 443-451, 2016.

[13] R. Zizzo, J. Kyriazis, and H. Goodland, Embodied Carbon of Buildings and Infrastructure: International Policy Review, Forestry Innovation Investment Ltd., Vancouver, British Columbia, 2017.

[14] C. Cao, "21-Sustainability and life assessment of high strength natural fibre composites in construction," Advanced High Strength Natural Fibre Composites in Construction, Elsevier, Amsterdam, Netherlands, pp. 529-544, 2017.

[15] L. Ben-Alon, V. Loftness, K. A. Harries, G. DiPietro, and E. C. Hameen, "Cradle to site Life Cycle Assessment (LCA) of natural vs conventional building materials: a case study on cob earthen material," Building and Environment, vol. 160, Article ID 106150, 2019.

[16] Mantle314, “Mass timber's carbon impact," 2020, https:// mantle314.com/insights/mass-timber-carbon-impact.

[17] S. Shaked and O. Jolliet, "Global life cycle impacts of consumer products," Encyclopedia of Environmental Health, Elsevier, Amsterdam, Netherlands, pp. 1002-1014, 2011.

[18] EN 1995-1-1, Eurocode 5: Design of Timber Structures Part 11: General-Common Rules and Rules for Buildings, CEN European Committee for Standardization, Brussels, Belgium, 2009.

[19] S. Cuerrier-Auclair, Design Guide for Timber-Concrete Composite Floors in Canada, Special Publication SP-540E, FPInnovations, Pointe-Claire, QC, Canada, 2020.

[20] M. A. H. Mirdad, Structural performance of Mass Timber Panel-Concrete (MTPC) composite floor system with inclined self-tapping screws and an insulation layer, Ph.D. thesis, Department of Civil \& Environmental Engineering, University of Alberta, Edmonton, AB, Canada, 2020.

[21] M. A. H. Mirdad, Y. H. Chui, and D. Tomlinson, "Capacity and failure mode prediction of mass timber panel-concrete composite floor system with mechanical connectors," Journal of Structural Engineering, vol. 147, no. 2, Article ID 04020338, 2020.

[22] M. A. H. Mirdad, Y. H. Chui, D. Tomlinson, and Y. Chen, "Bending stiffness and load-deflection response prediction of mass timber panel-concrete composite floor system with mechanical connectors," Journal of Performance of Constructed Facilities, 2021.

[23] C. Zhang and P. Gauvreau, "Timber-concrete composite systems with ductile connections," Journal of Structural Engineering, vol. 141, no. 7, Article ID 04014179, 2015.

[24] M. A. H. Mirdad and Y. H. Chui, "Strength prediction of mass-timber panel-concrete composite connection with inclined screws and a gap," Journal of Structural Engineering, vol. 146, no. 8, Article ID 04020140, 2020.

[25] M. A. H. Mirdad and Y. H. Chui, "Stiffness prediction of Mass Timber Panel-Concrete (MTPC) composite connection with inclined screws and a gap," Engineering Structures, vol. 207, Article ID 110215, 2020.

[26] S. R. S. Monteiro, A. M. P. G. Dias, and S. M. R. Lopes, "Transverse distribution of internal forces in timber-concrete floors under external point and line loads," Construction and Building Materials, vol. 102, pp. 1049-1059, 2016.

[27] C. Higgins, A. R. Barbosa, and C. Blank, "Structural tests of concrete composite-cross-laminated timber floors," Report 17-01, Oregon State University, Corvallis, OR, USA, 2017.

[28] K. Holschemacher, S. Klotz, and D. Weisse, "Application of steel fibre reinforced concrete for timber-concrete composite constructions," Lacer, vol. 7, pp. 161-170, 2002.

[29] J. Skinner, R. Harris, K. Paine, P. Walker, and J. Bregulla, "Ultra-thin topping upgrades for improved serviceability performance," Advanced Materials Research, vol. 778, pp. 673-681, 2013.

[30] A. M. P. G. Dias, S. M. R. Lopes, J. W. G. Van de Kuilen, and H. M. P. Cruz, "Load-carrying capacity of timber-concrete joints with dowel-type fasteners," Journal of Structural Engineering, vol. 133, no. 5, pp. 720-727, 2007.

[31] A. M. P. G. Dias, H. M. P. Cruz, S. M. R. Lopes, and J. W. van de Kuilen, "Stiffness of dowel-type fasteners in timber-concrete joints," Proceedings of the Institution of Civil Engineers - Structures and Buildings, vol. 163, no. 4, pp. 257-266, 2010.

[32] P. Hamm, A. Richter, and S. Winter, "Floor vibrations - new results," in Proceedings of the World Conference on Timber Engineering (WCTE), Riva del Garda, Italy, 2010.

[33] L. Hu, S. Cuerrier-Audair, Y. H. Chui et al., "Design method for controlling vibrations of wood-concrete composite floor systems," in Proceedings of the World Conference on Timber Engineering (WCTE), Vienna, Austria, 2016.

[34] CSA O86-19, Engineering Design in Wood, Canadian Standards Association, Mississauga, Canada, 2019.

[35] T. Joyce, H. Daneshvar, Y. H. Chui, and L. Zhang, "Optimizing mass timber-concrete composite floor systems with respect to embodied carbon," in Proceedings of the 2nd International Conference on New Horizons in Green Civil Engineering (NHICE-02), Victoria, British Columbia, 2020.

[36] L. Hu, Y. H. Chui, P. Hamm, T. Toratti, and T. Orskaug, "Development of ISO baseline vibration design method for timber floors," in Proceedings of the World Conference on Timber Engineering (WCTE), Seoul, Republic of Korea, 2018.

[37] NBCC, National Building Code of Canada, National Research Council, Ottawa, Canada, 2015.

[38] M. Schmid, "Acoustic performance of timber concrete composite floors," in Proceedings of the International Congress and Exposition on Noise Control Engineering 2005 (INTERNOISE 2005), Rio de Janeiro, Brazil, August 2005.

[39] Rothoblaas, "Silent floor-resilient underscreed foil made of bitumen and polyester felt," 2021, https://www.rothoblaas.com/ products/soundproofing/soundproofing-layers/silent-floor.

[40] Athena, Athena Impact Estimator for Buildings v5.4 Software and Database, Athena Sustainable Materials Institute, Ontario, Canada, 2019.

[41] A.-B. Laurent, S. Gaboury, J.-R. Wells et al., "Cradle-to-gate life-cycle assessment of a glued-laminated wood product from Quebec's Boreal forest," Forest Products Journal, vol. 63, no. 56, pp. 190-198, 2013.

[42] A.-B. Laurent, J.-F. Menard, P. Lesage, and R. Beauregard, "Cradle-to-gate environmental life cycle assessment of the portfolio of an innovative forest products manufacturing unit," BioResources, vol. 11, no. 4, pp. 8981-9001, 2016. 
[43] Structurlam, "Environmental product declaration: CrossLam CLT by Structurlam," 2021, https://www.astm.org/CERTIFICATION/ DOCS/480.EPD_FOR_Structurlam_CLT_20200113.pdf.

[44] Nordic structures, "Environmental Product Declaration: Nordic X-LamTM,” August 2018, https://www.nordic.ca/ data/files/datasheet/file/EPD_Nordic_X-Lam.pdf. 